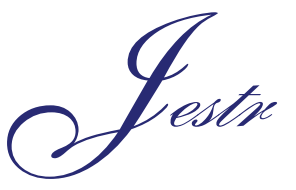

\title{
Application of Soft Computing for the Prediction of Warpage of Plastic Injection Molded Parts
}

\author{
B. Sidda Reddy ${ }^{1, *}$, J. Suresh Kumar ${ }^{2}$, Vijaya Kumar Reddy ${ }^{2}$ and G. Padmanabhan ${ }^{3}$ \\ ${ }^{1}$ Department of Mechanical Engineering, R. G. M. College of Engineering \& Technology, \\ Nandyal, Kurnool (Dt), A.P-518 501, India. \\ ${ }_{2}^{2}$ Mechanical Engineering, J.N.T University, Hyderabad, India. \\ ${ }^{3}$ Mechanical Engineering, S.V. University College of Engineering, S.V. University, Tirupati, A.P. India.
}

Received 4 October 2008; Accepted 15 June 2009

\begin{abstract}
This paper deals with the development of accurate warpage prediction model for plastic injection molded parts using soft computing tools namely, artificial neural networks and support vector machines. For training, validating and testing of the warpage model, a number of MoldFlow (FE) analyses have been carried out using Taguchi's orthogonal array in the design of experimental technique by considering the process parameters such as mold temperature, melt temperature, packing pressure, packing time and cooling time. The warpage values were found by analyses which were done by MoldFlow Plastic Insight (MPI) 5.0 software. The artificial neural network model and support vector machine regression model have been developed using conjugate gradient learning algorithm and ANOVA kernel function respectively. The adequacy of the developed models is verified by using coefficient of determination. To judge the ability and efficiency of the models to predict the warpage values absolute relative error has been used. The finite element results show, artificial neural network model predicts with high accuracy compared with support vector machine model.
\end{abstract}

Keywords: Plastic Injection Molding, Warpage, Artificial Neural Networks and Support Vector Machines.

\section{Introduction}

Plastic materials are commonly used in every area of the industry. The most important reason for this is the material properties of the plastics. Some of these properties are lightness, resistance to corrosion, ease to give shape. The most important is their physical and chemical properties can be changed as desired. Plastic materials can be used in packaging, aerospace, aviation, building and construction, automotive, agriculture, irrigation, sanitation, electrical conduits, and chemical processing plants etc. Plastic Injection Molding (PIM) is considered the most prominent process for mass producing plastic parts. More than one third of all plastic products are made by injection molding, and over half of the world's polymer processing equipment is used for the injection molding process. Plastic injection molding is one of the manufacturing processes carried out by a consecutive five phases with plastication, injection, packing, cooling and ejection. This process is complex but highly efficient means of producing a wide variety of three dimensional thermoplastic parts in a large volume of production. During production, quality problems of the plastic parts such as warpage, shrinkage, weld and meld lines, flow mark, flash, sink mark and void are affected from manufacturing proc-

* E-mail address: sidhareddy548@gmail.com ISSN: 1791-2377 (C) 2009 Kavala Institute of Technology. All rights reserved. ess conditions which include the melt temperature, mold temperature, injection pressure, injection velocity, injection time, packing pressure, packing time, cooling time, cooling temperature etc. One of the most important quality problems is warpage. Warpage, is a distortion of the shape of the final injection-molded item, is caused by differential shrinkage; that is, if one area or direction of the article undergoes a different degree of shrinkage than another area or direction, the part will warp.

During plastication, injection, packing, cooling and ejection processes, the residual stress is produced due to high pressure, temperature change, and relaxation of polymer chains, resulting in warpage of the part. In order to yield a product with high precision, optimum mold geometry and processing parameters must be found. To reduce the cost and time at the design stage, it is important to simulate warpage of the injection molded part. In this study, the warpage values were found by analyses which were done by a computer aided engineering software MoldFlow Plastic Insight (MPI) 5.0. A predictive model for warpage in terms of the process parameters is then developed by artificial neural networks (ANN) and support vector machines (SVM). The developed model is validated and tested with some of the FE results, which were not used for developing the model. 


\section{Literature Review}

In the past, Jacques [1] analyzed thermal warpage in injection molded flat parts due to unbalanced cooling. Akay and Ozden [2] measured thermal residual stresses and distortions of injection molded parts and analyzed the effects of temperature gradients. Liu [3] simulated and predicted the residual stress and warpage using a viscoelastic phase transformation model, which assumed the solidified polymer to be a linear solid and the polymer melt to be a viscous fluid. Bushko and Stokes [4-5] used the solidification of a molten layer of amorphous thermoplastic between cooled parallel plates to model the mechanics of part shrinkage, warpage and the build-up of residual stresses during the injection molding process, assuming thermoviscoelastic behavior of the material. Kabanemi et al. [6-7] simulated residual stresses and residual deformations using three-dimensional finite element method for a thermo-viscoelastic model and applied it to a complex shape. Matsuoka et al. [8] developed an injection molding analysis program considering mold cooling and polymer filling-packing-cooling to predict warpage. Hastenberg et al. [9] measured the residual stress distributions in injection molded flat plates using a modified layerremoval method. Jansen et al. [10] systematically studied the effect of processing conditions such as holding pressure, injection velocity, and mold and melt temperatures on shrinkage. Jansen and Titomanlio [11-12] calculated residual stresses and shrinkage of thin products using an elastic model to study the effect of inmold shrinkage on the final product dimensions and measured the shrinkage under various molding conditions. Choi and Yong-Taek [13] analyzed for shrinkage and warpage using a linear elastic three dimensional finite element method.

In the present investigation, the plastic elbow part has been chosen for the prediction of warpage. A predictive model for warpage in terms of the process parameters such as mold temperature, melt temperature, packing pressure, packing time and cooling time is then developed using artificial neural networks and support vector machines. The developed model is validated and tested with some of the FE results, which were not used for developing the model. ANN and SVM predicted results are in good agreement with finite element results of warpge. The finite element results show, artificial neural network model predicts with high accuracy compared with support vector machine model.

\section{Experimental Details}

The Taguchi's orthogonal array has been implemented for warpage analyses by considering the process parameters such as mold temperature, melt temperature, packing pressure, packing time and cooling time. The simulation model of elbow plastic part with mesh geometry and injection location, shown in Fig.1 was created. The geometry of this elbow plastic part was discretized using fusion mesh by MoldFlow, which is commercial software based on hybrid finite element method for solving pressure, flow and temperature fields. The part is made of Indothene 24-MA-040. The Shrinkage of this material is of the order of $0.02-0.05 \mathrm{~mm} / \mathrm{mm}(2$ $-5 \%$ ) when density is between $0.91-0.925 \mathrm{~g} / \mathrm{cm}^{3}$. When density is between $0.926-.04 \mathrm{~g} / \mathrm{cm}^{3}$, the shrinkage is of the order of $1.5-4 \%$. Actual shrinkage values are dependent on the molding conditions.
Finite Element analyses of the elbow part are performed using commercial software MoldFlow Plastic Insight 5.0 for the combination of process parameters shown in Table 1 . The combination of process parameters generated by three-level Taguchi's orthogonal array [14]. Finite Element analyses have been carried out for the manufacturing parameters presented in Table 2 . The analyses have been carried out on a Genuine Intel x86 Family 6 Model 14 Stepping $12 \sim 17$ processor PC. The warpage values of 36 experiments, for the combination of process parameters are shown in Fig.2.

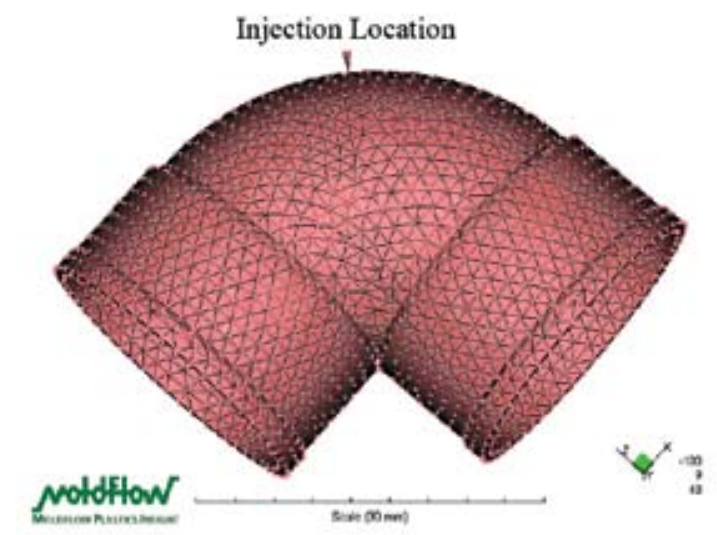

Figure 1. Elbow part with mesh geometry and injection location

Table 1. Process parameters and their levels

\begin{tabular}{lcccc}
\hline Control parameter & Units & \multicolumn{3}{c}{ Levels } \\
\cline { 3 - 5 } & & Level 1 & Level 2 & Level 3 \\
\hline Mold Temperature (M OT) & ${ }^{0} \mathrm{C}$ & 40 & 50 & 60 \\
Melt Temperature (MET) & ${ }^{0} \mathrm{C}$ & 175 & 190 & 205 \\
Packing Pressure (PP) & $\mathrm{MPa}$ & 90 & 110 & 130 \\
Packing Time (PT) & $\mathrm{sec}$ & 2 & 4 & 6 \\
Cooling Time (CT) & $\mathrm{sec}$ & 20 & 25 & 30 \\
\hline
\end{tabular}

Table 2. Manufacturing parameters employed in Moldflow analysis

\begin{tabular}{lc}
\hline Injection time & $1.287 \mathrm{~s}$ \\
Injection pressure & $90 \mathrm{MPa}$ \\
Cooling channel diameter & $10 \mathrm{~mm}$ \\
Between cooling channels center distance & $55 \mathrm{~mm}$ \\
Between cooling channel's & \\
Center-parting surface distance & $25 \mathrm{~mm}$ \\
Upper inlet water temperature & $40^{\circ} \mathrm{C}$ \\
Lower inlet water temperature & $14^{\circ} \mathrm{C}$ \\
Number of gate & 4 \\
\hline
\end{tabular}

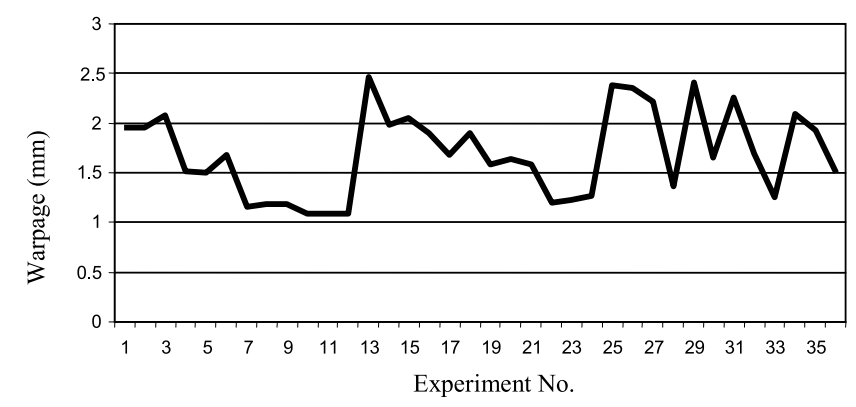

Figure 2. Finite Element results of warpage of 36 Experiments 


\section{Modeling of Plastic Injection Molding Process}

\subsection{Artificial neural network model for warpage}

The use of artificial neural networks (ANN) has been well accepted in the areas of telecommunication, signal processing, pattern recognition, prediction, process control and financial analysis [15]. An ANN is an information processing system that behaves similarly to a biological neural network. It is made up of highly processing units called neurons that are classified into three layers: input layer, hidden layer, and output layer. Each of these neurons applies an activation function to the net input signal. Information is transferred from one neuron to another by connection links. Each connection link applies an associated multiplier, called a weight. A bias, another weight, is added to the sum of all products pertaining to the incoming links. Determination of these weights called training is the most significant task.

$$
\text { net }_{j}=\sum_{j=0}^{N} W_{i j} X_{i}
$$

Where net $t_{j}$ is the total or net input and $\mathrm{N}$ is the number of inputs to the $\mathrm{j}^{\text {th }}$ neuron in the hidden layer. $\mathrm{W}_{\mathrm{ij}}$ is the weight of the connection from the $\mathrm{i}^{\text {th }}$ neuron in the forward layer to the $\mathrm{j}^{\text {th }}$ neuron in the hidden layer. A neuron in the network produces its output (Out ${ }_{\mathrm{j}}$ ) by processing the net input through an activation (Transfer) function $\mathrm{f}$, such as logistic function as given as follows.

$$
\mathrm{Out}_{\mathrm{j}}=\mathrm{f}\left(\text { net }_{\mathrm{j}}\right)=\frac{1}{1+\mathrm{e}^{-n e t j}}
$$

The neural network architecture 5-12-10-1 was used in this study is shown in Fig 3. It was designed using NeuroIntelligence software [16]. The network consists of one input, two hidden and one out put layer. Hidden layer one, has twelve neurons and second hidden layer has ten neurons, where as the input and output layers have five and one neuron respectively. Since warpage prediction in terms of mold temperature, melt temperature packing pressure, packing time and cooling time was the main interest in this research, neurons in the input layer corresponding to the mold temperature, melt temperature packing pressure, packing time and cooling time, the output layer corresponds to warpage.

\subsubsection{Generation of Train, Validation and Test Data}

To calculate the connection weights, a set of desired network output values are needed. Desired output values are called the training data set. Training data set is a part of input data set used for neural network training, i.e. to adjust network weights for maximizing predictive ability and minimizing forecasting error. In this study, 26, 5 and 5 finite element results of warpage data were used as training, validating and testing of the network respectively and given in Table 3, Table 4 and Table 5.

\subsubsection{Network Training}

Calculation of weights and biases to the variables is called net-

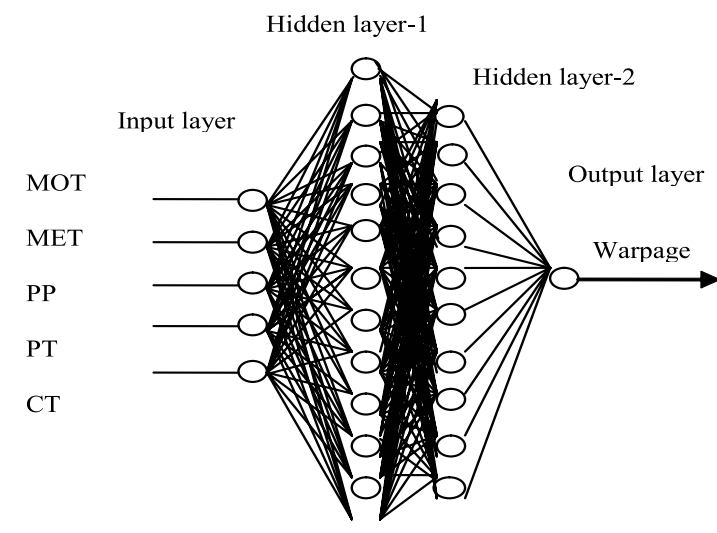

Figure 3. Neural network architecture designed

work training. The training phase of a back - propagation network is an unconstrained nonlinear optimization problem. The goal of the training is to search an optimal set of connection weights in the manner that the errors of the network output can be minimized. There are several algorithms that can be used to determine the weights and biases for the network. Besides popular steepest descent algorithm, conjugate gradient algorithm is another search method that can be used to minimize network output error in conjugate directions. The Conjugate Gradient Method is the most prominent iterative method for solving sparse systems of linear equations. This is an advanced method for training multi-layer neural networks. The conjugate gradient method can be used to minimize any continuous function $\mathrm{f}(\mathrm{x})$ for which the gradient $\mathrm{f}^{\prime}$ can be computed. Conjugate gradient method uses orthogonal and linearly independent non-zero vectors. In this application the weights and biases are determined and updated using conjugate gradient descent method. The applications include a variety of application problems, such as engineering design, neural net training, and non linear regression. The conjugate gradient method is updated until convergence takes place i.e. minimize the mean square error (MSE) between the network prediction and training data set. The out line of the non-linear conjugate gradient method is given below.

Find $\lambda(t)$ that minimizes $E(\vec{w}(t+1))$

$\vec{w}(t+1)=\vec{w}(t)+\lambda(t) d(t)$

$d(t+1)=-g(t+1)+\beta(t) d(t)$

Where $\lambda(t)$ is the exact step to the minimum of $E(\vec{w}(t+1))$ along the direction of $d(t)$ and $\beta(t)$ is the step size to decide $d(t+1)$. All of the conjugate gradient algorithms start out by searching in the steepest descent direction (negative of the gradient) on the first iteration. $\mathrm{d}_{0}=-\mathrm{g}_{0}$

A line search is then performed to determine the optimal distance to move along the current search direction using equation (3).

The conjugate gradient method automatically selects an appropriate learning rate $\eta(t)$ and momentum factor $\alpha(t)$ in each epoch.

$\eta(\mathrm{t})=\lambda(\mathrm{t}) ; \alpha(\mathrm{t})=\lambda(\mathrm{t}) \beta(\mathrm{t})$ 
To judge the ability and efficiency of the models to predict the warpage values network error, absolute error and absolute relative error has been used. The difference between the actual value of the target column and the corresponding network output. The difference will be displayed in absolute values and in percentage terms. Absolute relative error is an error value that indicates the "quality" of the neural network training. This index is calculated by dividing the difference between actual and desired output values by the module of the desired output value. The smaller the network error is, the better the network had been trained.

The Network error, absolute error and absolute relative error obtained after training of the network with 50,000 epochs and multiple training (three times) is $0.004114,0.056707$ and $2.413125 \%$ respectively. The $\mathrm{R}^{2}$ value was found to be $96.098 \%$ which shows the correlation that is exists between the experimental and predicted values, i.e. how well the network outputs actual target values and also the training standard deviation was found to be 0.00006 . It is an expected deviation of values from a mathematic expectancy.

Table 3. Data set used in creating ANN and SVM model

\begin{tabular}{|c|c|c|c|c|c|}
\hline MOT & MET & PP & PT & CT & Warpage (mm) \\
\hline 40 & 175 & 90 & 2 & 20 & 1.956 \\
\hline 40 & 175 & 90 & 2 & 25 & 1.950 \\
\hline 40 & 190 & 110 & 4 & 25 & 1.501 \\
\hline 40 & 190 & 110 & 4 & 30 & 1.680 \\
\hline 40 & 205 & 130 & 6 & 20 & 1.160 \\
\hline 40 & 205 & 130 & 6 & 25 & 1.181 \\
\hline 40 & 205 & 130 & 6 & 30 & 1.179 \\
\hline 50 & 175 & 110 & 6 & 30 & 1.084 \\
\hline 50 & 190 & 130 & 2 & 20 & 2.462 \\
\hline 50 & 190 & 130 & 2 & 25 & 1.985 \\
\hline 50 & 190 & 130 & 2 & 30 & 2.052 \\
\hline 50 & 205 & 90 & 4 & 20 & 1.897 \\
\hline 50 & 205 & 90 & 4 & 30 & 1.897 \\
\hline 60 & 175 & 130 & 4 & 25 & 1.632 \\
\hline 60 & 175 & 130 & 4 & 30 & 1.589 \\
\hline 60 & 190 & 90 & 6 & 20 & 1.203 \\
\hline 60 & 190 & 90 & 6 & 25 & 1.229 \\
\hline 60 & 190 & 90 & 6 & 30 & 1.262 \\
\hline 60 & 205 & 110 & 2 & 20 & 2.375 \\
\hline 40 & 175 & 110 & 4 & 25 & 1.360 \\
\hline 40 & 190 & 90 & 2 & 30 & 2.410 \\
\hline 50 & 175 & 110 & 2 & 25 & 2.262 \\
\hline 50 & 190 & 110 & 4 & 25 & 1.696 \\
\hline 50 & 205 & 110 & 6 & 30 & 1.251 \\
\hline 60 & 175 & 90 & 2 & 25 & 2.096 \\
\hline 60 & 205 & 90 & 6 & 25 & 1.497 \\
\hline
\end{tabular}

Table 4. Data set used for validating ANN and SVM model

\begin{tabular}{cccccc}
\hline MOT & MET & PP & PT & CT & Warpage (mm) \\
\hline 40 & 175 & 90 & 2 & 30 & 2.084 \\
50 & 175 & 110 & 6 & 20 & 1.086 \\
60 & 175 & 130 & 4 & 20 & 1.589 \\
60 & 205 & 110 & 2 & 30 & 2.222 \\
60 & 190 & 110 & 4 & 25 & 1.929 \\
\hline
\end{tabular}

Table 5. Data set used for testing ANN and SVM model

\begin{tabular}{cccccc}
\hline MOT & MET & PP & PT & CT & Warpage $(\mathbf{m m})$ \\
\hline 40 & 190 & 110 & 4 & 20 & 1.510 \\
50 & 175 & 110 & 6 & 25 & 1.085 \\
40 & 190 & 110 & 4 & 30 & 1.680 \\
60 & 205 & 110 & 2 & 25 & 2.352 \\
40 & 205 & 110 & 4 & 25 & 1.652 \\
\hline
\end{tabular}

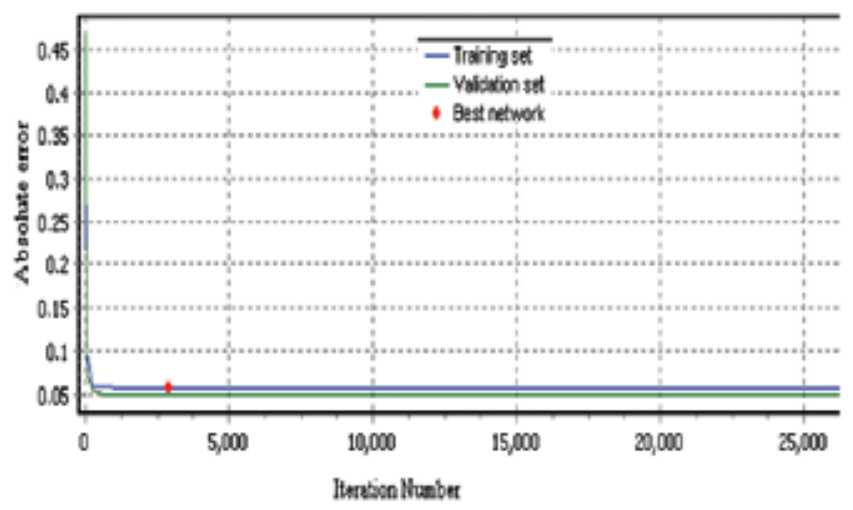

Figure 4. Absolute error for training and validation set

\subsubsection{Neural Network validation and Testing}

Once the weights are adjusted the performance of the trained network was validated and tested for the finite element results presented in Table 4 and Table 5 of warpage data which was never used in the training process. Validation set is a part of the data used to tune the network topology or network parameters other than weights. It is used to define the number of hidden units of to detect the moment when predictive ability of neural network started to deteriorate. Test set is a part of the input data set used only to test how well the neural network will forecast on new data. Test data set is used after network is ready (trained), to test what errors will occur during future forecasting. This set is not used during training and thus can be considered as though it consists of the new data entered by user for forecasting. The results predicted by the network for training, validating and testing were compared with the finite element analysis results presented in Table 6, Table 7 and Table 8. The absolute relative error, standard deviation for validating and testing data was found to be $3.020207 \%, 0.000335$, $4.423789 \%$, and 0.006641 respectively. The $\mathrm{R}^{2}$ value was found to be $95.95 \%$ for validation data and $93.4058 \%$ for test data. Fig 4 shows the absolute error for training, validation data.

\subsection{Support Vector Machine model for warpage}

The Support Vector algorithm is a nonlinear generalization of the generalized Portrait algorithm developed in Russia in the sixties. As such, it is firmly grounded in the framework of statistical learning theory, or VC theory, which has been developed over the last three decades by Vapnik and Chervonenkis [1974], Vapnik [1982, 1995]. In a nutshell, VC theory characterizes properties of learning machines which enable them to generalize well to unseen data.

Support Vector Machines (SVM) are very specific class of algorithms, characterized by usage of kernels, absence of local 
minima, sparseness of the solution and capacity control obtained by acting on the margin, or on number of support vectors, etc. SVM is an emerging technique pioneered by Vapnik [17]. It is an interdisciplinary field of machine learning, optimization, statistical learning and generalization theory. Basically, it can be used for pattern classification and non-liner regression. SVM considers the application of SVM as quadratic programming problem of the weights of various factors including regularization factor. Since a quadratic programming problem is a convex function, the solution of quadratic programming problem is global (or even unique) instead of a local solution. The advantages of SVM [18] are:

(1) The architecture of the system need not be determined before training. Input data of any arbitrary dimension can be treated only linearly regarding the relation of cost to the number of input dimensions.

(2) SVM treats regression as a quadratic programming problem of minimizing the data fitting error plus generalization, which produces a global solution having minimum fitting error, while high generalization of the estimated model can be obtained.

\subsubsection{SVM formulation for Non-linear regression}

Consider the regression on the data set, $\mathrm{D}=\left\{\left(\mathrm{x}_{1}, \mathrm{y}_{1}\right),\left(\mathrm{x}_{2}, \mathrm{y}_{2}\right)---\right.$ -------- $\left.\left(\mathrm{x}_{\mathrm{N}}, \mathrm{y}_{\mathrm{N}}\right)\right\}$, with $\mathrm{N}$ data points where $\mathrm{x}_{\mathrm{i}} \in \mathrm{R}^{\mathrm{n}} \mathrm{y} \in \mathrm{R}$. SVM formulation for non linear regression is expressed by the following equation [19].

$$
\begin{aligned}
& \operatorname{Min}_{\alpha, \alpha^{*}} \mathrm{w}\left(\alpha\left(\alpha^{*}\right)=\frac{1}{2} \sum_{\mathrm{i}=1}^{N} \sum_{j=1}^{N}\left(\alpha_{i}-\alpha_{i}^{*}\right)\left(\alpha_{j}-\alpha_{j}^{*}\right) \mathrm{k}\left(\mathrm{x}_{\mathrm{i}}, \mathrm{x}_{\mathrm{j}}\right)\right. \\
& +\varepsilon \sum_{i=1}^{N}\left(\alpha_{i}+\alpha_{i}^{*}\right)-\sum_{i=1}^{N} y_{i}\left(\alpha_{i}-\alpha_{i}^{*}\right)
\end{aligned}
$$

\section{Such that}

$$
\sum_{i=1}^{N}\left(\alpha_{i}-\alpha_{i}^{*}\right)=0
$$

Where $\alpha$ and $\alpha^{*}$ are the Lagrangian Multipliers (each multiplier is expressed as an $\mathrm{N}$-dimensional vector); $\alpha_{i}, \alpha_{j} \in \alpha, \alpha_{i}^{*}, \alpha_{j}^{*} \in \alpha^{*}$, for $1 \leq \mathrm{i}, \mathrm{j} \leq \mathrm{N}$ and $\alpha_{i}, \alpha_{j}, \alpha_{i}^{*} \alpha_{j}^{*} \in[0, \mathrm{C}]$. k, kernel function, $\varepsilon$, user pre defined regularization constant; $\mathrm{C}$, user pre-defined positive real constant for capacity control.

From the view point of the present study some parameters in equation (5) are specified as. N, total number of FE results (data points); $\mathrm{x}_{\mathrm{i}}$, input process parameters in the $\mathrm{i}^{\text {th }}$ sample data point, $i=1,2$, -------N (i.e. $i^{\text {th }}$ process setup), $y_{i}$, process output warpage in the $\mathrm{i}^{\text {th }}$ sample data point.

$\alpha_{i}$ and $\alpha_{i}{ }^{*}$ are known as support values corresponding to the $\mathrm{i}^{\text {th }}$ data point, where $\mathrm{i}^{\text {th }}$ data point means the $\mathrm{i}^{\text {th }}$ process setup and output warpage. Besides, ANOVA kernel function has been used for non linear regression.

The ANOVA kernel is constructed by considering $\mathrm{X}=\mathrm{S}^{\mathrm{N}}$ for the set ' $\mathrm{S}$ ' and kernels $\mathrm{k}^{(\mathrm{i})}$ on $\mathrm{S} \times \mathrm{S}$, where $\mathrm{i}=1,2,----\mathrm{N}$, for $\mathrm{p}=1,2$,-
-----N. The ANOVA kernel order P is defined as

$$
\mathrm{k}_{\mathrm{p}}\left(\mathrm{x}, \mathrm{x}^{\prime}\right)=\sum_{1 \leq \mathrm{i}_{1} \leq---\mathrm{i}_{\mathrm{p}} \leq \mathrm{N}} \prod_{\mathrm{p}=1}^{\mathrm{P}} \mathrm{k}\left(\mathrm{i}_{\mathrm{p}}\right)\left(\mathrm{x}_{\mathrm{ip}}, \mathrm{x}_{\mathrm{ip}}^{\prime}\right)
$$

If $\mathrm{P}=\mathrm{N}$, the sum consists of only of the term for which ( $\mathrm{i}_{1}$, $\left.----i_{p}\right)=(1,---N)$ and $k$ equals the tensor product $k^{(1)} \otimes------\otimes$ $\mathrm{k}^{(\mathrm{N})}$. At the other extreme, if $\mathrm{P}=1$, then the products collapse to one factor each, and $k$ equals the direct sum $\mathrm{k}^{(1)} \oplus$------ $\oplus \mathrm{k}^{(\mathrm{N})}$. For intermediate values of $\mathrm{P}$, the kernels lie in between tensor products and direct sums.

The non linear model is given as:

$M(x)=\sum_{i=1}^{N}\left(\alpha_{i}-\alpha_{i}^{*}\right) k\left(x, x_{i}\right)+b$

Table 6. Comparison of warpage of FE, ANN and SVM results for training data

\begin{tabular}{ccccr}
\hline $\begin{array}{c}\text { FE } \\
\text { Out Put } \\
(\mathbf{m m})\end{array}$ & $\begin{array}{c}\text { ANN } \\
\text { Out Put } \\
\text { (mm) }\end{array}$ & $\begin{array}{c}\text { \% Error } \\
\text { of FE and } \\
\text { ANN }\end{array}$ & $\begin{array}{c}\text { SVM } \\
\text { Out Put } \\
\text { (mm) }\end{array}$ & $\begin{array}{c}\text { \% Error } \\
\text { of FE and } \\
\text { SVM }\end{array}$ \\
\hline 1.956 & 1.95757 & 0.0801 & 1.956 & 0.0000 \\
1.950 & 1.95757 & 0.3880 & 1.950 & 0.0000 \\
1.501 & 1.58351 & 5.4970 & 1.251 & 16.6556 \\
1.680 & 1.58351 & 5.7434 & 1.680 & 0.0000 \\
1.160 & 1.17906 & 1.6431 & 1.160 & 0.0000 \\
1.181 & 1.17906 & 0.1643 & 1.181 & 0.0000 \\
1.179 & 1.17906 & 0.0051 & 1.360 & 15.3520 \\
1.084 & 1.10153 & 1.6169 & 1.084 & 0.0000 \\
2.462 & 2.18337 & 11.3172 & 2.410 & 2.1121 \\
1.985 & 2.18337 & 9.9935 & 1.696 & 14.5592 \\
2.052 & 2.18337 & 6.4021 & 2.052 & 0.0000 \\
1.897 & 1.89969 & 0.1417 & 1.897 & 0.0000 \\
1.897 & 1.89969 & 0.1417 & 1.897 & 0.0000 \\
1.632 & 1.61184 & 1.2351 & 1.632 & 0.0000 \\
1.589 & 1.61184 & 1.4376 & 1.589 & 0.0000 \\
1.203 & 1.22991 & 2.2368 & 1.203 & 0.0000 \\
1.229 & 1.22991 & 0.0739 & 1.262 & 2.6851 \\
1.262 & 1.22991 & 2.5429 & 1.262 & 0.0000 \\
2.375 & 2.35864 & 0.6888 & 2.375 & 0.0000 \\
1.360 & 1.35761 & 0.1755 & 1.179 & 13.3088 \\
2.410 & 2.39191 & 0.7506 & 2.497 & 3.6100 \\
2.262 & 2.14088 & 5.3544 & 2.229 & 1.4589 \\
1.696 & 1.69626 & 0.0150 & 2.096 & 23.5849 \\
1.251 & 1.27119 & 1.6139 & 1.501 & 19.9840 \\
2.096 & 2.16039 & 3.0721 & 1.985 & 5.2958 \\
1.497 & 1.49085 & 0.4106 & 1.462 & 2.3380 \\
\hline Absolute relative error & & Absolute relative error \\
& $=2.413125 \%$ & & $=4.651704 \%$ \\
\hline & & & & \\
\hline
\end{tabular}

Table 7. Comparison of warpage of FE, ANN and SVM results for Validation data

\begin{tabular}{ccccc}
\hline $\begin{array}{c}\text { FE } \\
\text { Out Put } \\
(\mathbf{m m})\end{array}$ & $\begin{array}{c}\text { ANN } \\
\text { Out Put } \\
(\mathbf{m m})\end{array}$ & $\begin{array}{c}\text { \% Error } \\
\text { of FE and } \\
\text { ANN }\end{array}$ & $\begin{array}{c}\text { SVM } \\
\text { Out Put } \\
\text { (mm) }\end{array}$ & $\begin{array}{c}\text { \% Error } \\
\text { of FE and } \\
\text { SVM }\end{array}$ \\
\hline 2.084 & 1.95757 & 6.06689 & 2.00622 & 3.73225 \\
1.086 & 1.10153 & 1.42974 & 1.11089 & 2.29190 \\
1.589 & 1.61184 & 1.43759 & 1.63718 & 3.03210 \\
2.222 & 2.35864 & 6.14945 & 2.26082 & 1.74707 \\
1.929 & 1.92867 & 0.01737 & 1.73659 & 9.97460 \\
\hline \multicolumn{3}{c}{ Absolute relative error } \\
$=3.020207 \%$ & & $\begin{array}{c}\text { Absolute relative error } \\
=4.155583 \%\end{array}$ \\
\hline
\end{tabular}


Table 8. Comparison of warpage of FE, ANN and SVM results for Test data

\begin{tabular}{ccccc}
\hline $\begin{array}{c}\text { FE } \\
\text { Out Put } \\
(\mathbf{m m})\end{array}$ & $\begin{array}{c}\text { ANN } \\
\text { Out Put } \\
(\mathbf{m m})\end{array}$ & $\begin{array}{c}\text { \% Error } \\
\text { of FE and } \\
\text { ANN }\end{array}$ & $\begin{array}{c}\text { SVM } \\
\text { Out Put } \\
(\mathbf{m m})\end{array}$ & $\begin{array}{c}\text { \% Error } \\
\text { of FE and } \\
\text { SVM }\end{array}$ \\
\hline 1.510 & 1.58351 & 4.8682 & 1.63050 & 7.98013 \\
1.085 & 1.10153 & 1.5232 & 1.11089 & 2.38618 \\
1.680 & 1.89969 & 13.0767 & 1.79407 & 6.78988 \\
2.352 & 2.35864 & 0.2823 & 2.26082 & 3.87670 \\
1.652 & 1.69113 & 2.3684 & 1.71677 & 3.92070 \\
\hline \multicolumn{3}{c}{ Absolute relative error } & \multicolumn{3}{c}{$\begin{array}{c}\text { Absolute relative error } \\
=4.423789 \%\end{array}$} \\
\multicolumn{4}{c}{$=4.990718 \%$} \\
\hline
\end{tabular}

Fig 5, 6, and 7 shows the comparison of Finite element results with artificial neural networks and support vector machines for training, validating and testing of warpage results respectively.

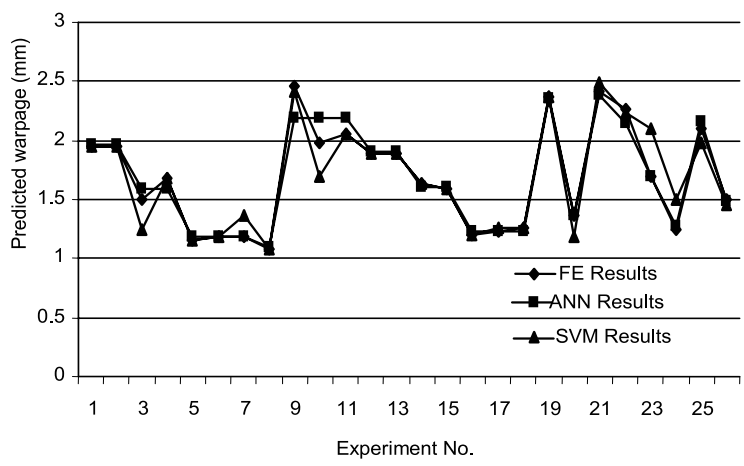

Figure 5. Comparison of FE, ANN \& SVM Results for training

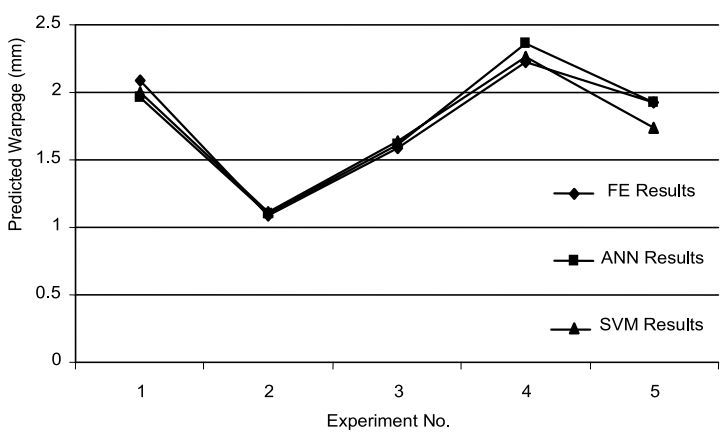

Figure 6. Comparison of FE, ANN \& SVM Results for Validation

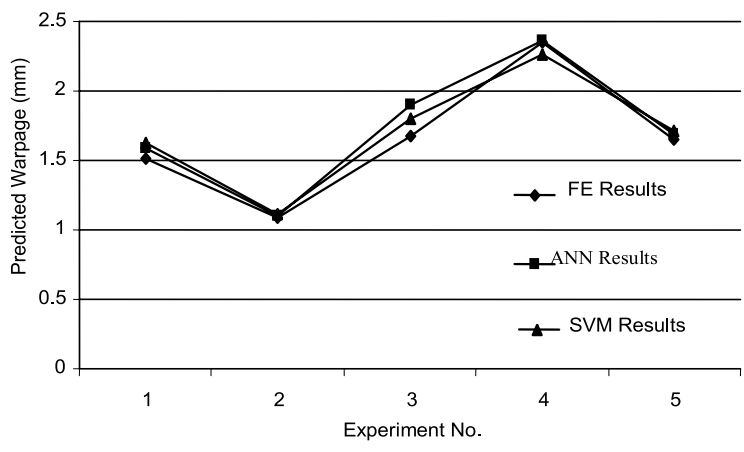

Figure 7. Comparison of FE, ANN \& SVM Results for Test Data

\section{Extensions and Future Studies}

This paper can be further extended by considering the more number of input process parameters such as injection velocity, injection time, runner types, gate location together with the process parameters of the mold temperature, melt temperature, packing pressure, packing time and cooling time to study the effect of warpae of injection molded parts. The application of soft computing techniques namely artificial neural networks and support vector machines can also be employed to predict the warpge of other thin shell plastic parts having complex geometry. This paper can be further extended by considering the more number of output characteristics such as shrinkage, sink index, weld and meld lines, flow mark, flash, sink mark and void etc together with warpage for the input process parameters such as injection velocity, injection time, runner types, gate location together with the process parameters of the mold temperature, melt temperature, packing pressure, packing time and cooling time.

\section{Conclusions}

Warpage values were found by analyses which were done by a computer aided engineering software MoldFlow plastic insight (MPI) 5.0 software using Taguchi's orthogonal array. Based on the Finite element results and the results predicted by artificial neural networks and support vector machines, the following conclusions are drawn.

1. Artificial neural network model and support vector machines model for warpage has been developed by considering the process parameters namely, mold temperature, melt temperature, packing pressure, packing time and cooling time.

2. The results predicted by artificial neural networks and support vector machines for training, validation and test data, are compared with the simulation results.

3. The artificial neural network model could predict the warpage $(\mathrm{mm})$ with absolute relative error of $2.413125 \%$ or $97.586875 \%$ accuracy from training data set, 3.020207\% or $96.979793 \%$ accuracy from validating data set and $4.423789 \%$ or $95.576211 \%$ from testing data.

4. The support vector machine model could predict the warpage $(\mathrm{mm})$ with absolute relative error of $4.651704 \%$ or $95.348296 \%$ accuracy form training data set, $4.155583 \%$ or $95.844417 \%$ accuracy from validating data set, and $4.990718 \%$ or $95.009282 \%$ from testing data.

5. The absolute relative error predicted by the artificial neural networks and support vector machines is less than $5 \%$. Hence, the ANN and SVM predicted results are in good agreement with finite element results of warpge.

6. From the absolute relative error, it is concluded that the artificial neural networks predicts with high accuracy compared with support vector machines.

\section{Acknowledgement}

The Author would like to thank Mr. K. Ramaiah, plant in charge of Nandi PVC fittings and also to Hon'ble Chairman Dr. M.Santhi Ramudu, Managing Director Mr. M. Sivaram, Principal Dr. T. Jaya Chandra Prasad Rajeev Gandhi memorial College of Engg \& Technology, Nandyal and Head of the Mech Engg Dept. for providing the facilities to carry out the research work. 


\section{References}

1. M.Jacques. An analysis of warpage in injection molded flat parts due to unbalanced cooling. Polym Eng Sci. 22(4):241-7, 1982.

2. M. Akay, S. Ozden, T. Tansey. Prediction of process-induced warpage in injection molded thermoplastics. Polym Eng Sci. 36(13):1839-46, 1996

3. S.J. Liu. Modeling and simulation of thermally induced stress and warpage in injection molded thermoplastics. Polym Eng Sci. 36(6):807-18, 1996.

4. W.C. Bushko, V.K. Stokes. Solidification of thermoviscoelastic melts. Part I: Formulation of model problem. Polym Eng Sci. 35(4):351-64, 1995.

5. W.C. Bushko, V.K. Stokes. Solidification of thermoviscoelastic melts Part II: Effects of processing conditions on shrinkage and residual stresses. Polym Eng Sci. 35(4):365-83, 1995.

6. K.K. Kabanemi, M.J. Crochet. Thermoviscoelastic calculation of residual stresses and residual shape of injection molded parts. Int Polym Process. 7:60-70, 1992.

7. K.K Kabanemi, H. Vallancourt, H. Wang, G. Salloum. Residual stresses, shrinkage, and warpage of complex injection molded products: numerical simulation and experimental validation. Polym Eng Sci. 38(1):21-37, 1998.

8. T. Matsuoka, J. Takabatake, A. Koiwai, Y. Inoue, S. Yamamoto, H. Takahashi. Integrated simulation to predict warpage of injection molded parts. Polym Eng Sci. 31(14):1043-50, 1991

9. C.H.V. Hastenberg, P.C. Wildervanck, A.J.H. Leanen. The measurement of thermal stress distribution along the flow path in injection-molded flat plates. Polym Eng Sci. 32(7):506-15, 1992.

10. K.M.B. Jansen, D.J.V. Dijk, M.H. Husselman. Effect of processing conditions on shrinkage in injection molding. Polym Eng Sci. 38(5):838-46, 1998.
11. K.M.B. Jansen, G. Titomanlio. Effect of pressure history on shrinkage and residual stresses-injection molding with constrained shrinkage. Polym Eng Sci. 36(15):2029-40, 1996.

12. G. Titomanlio, K.M.B. Jansen. In-mold shrinkage and stress prediction in injection molding. Polym Eng Sci. 36(5):2041-9, 1996.

13. Du-Soon Choi, Im. Yong-Taek. Prediction of Shrinkage and Warpage in consideration of residual stress in integrated simulation of injection molding. Int. J. Composite Structures. 47:655-665, 1999.

14. P.J. Ross. Taguchi techniques for quality engineering. McGraw-Hill, New York, 1996.

15. C.-H Wu, and W.-J. Liang. Effects of geometry and injection molding parameters on weld-line strength. Polymer Engineering and Science. 45 (7): 1021-1030, 2005.

16. ALYUDA Neurointelligence Manual, 2005. http://www.alyuda.com

17. N. Cristianini, J. Shawe-Taylor. An Introduction to Support Vector Machines and other Kernel based learning methods, Cambridge University Press, 2000.

18. A. Smola, C. Burges, H. Drucker, S. Golowich, L. van Hemmen, K. Muller, B. Scholkopf, and V. Vapnik. Regression Estimation with support vector Learning machines, 1996. Available at http://www.first.gmd. de/ smola.

19. S. Gunn. Support Vector machines for classification and regression. ISIS Technical report ISIS-1-98. Image speech and intelligent system research group, University of Southampton, U.K, 1998.

20. winSVM manual, 2005. Available at http://www.cs.ucl.ac.uk/staff/M. Sewell/winsvm 